Filo. y Lingüí. 9 (1): 67-74, 1983.

\title{
ACTITUD CRITICA EN EL COSTUMBRISMO COSTARRICENSE
}

Alvaro Quesada Soto

Es generalmente aceptado por nuestra crítica literaria el que hacia 1900, las manifestaciones costumbristas, que habían aparecido esporádicamente en los periódicos y revistas costarricenses de la época, adquieren, en los cuentos de Magón y las "Concherías" de Aquileo, una forma literaria definitiva, que convierte a estos autores en nuestros primeros clásicos. "La literatura costarricense - nos dice Abelardo Bonilla- nace con el realismo en los últimos años del siglo $\mathrm{XIX}$ y en los primeros del actual. En un sentido estricto no hubo literatos antes" (1).

Las principales características del costumbrismo han sido ya debidamente estudiadas, señaladas y analizadas por diversos investigadores de nuestra literatura. No es nuestro propósito volver sobre ellas. Lo que nos interesa en este artículo es más bien destacar una faceta casi desapercibida y un poco clandestina del costumbrismo. Esta faceta, que denominaremos "actitud crítica", se opone a la actitud eminentemente anecdótica y acrítica que predomina en el mundo literario del costumbrismo.

La actitud crítica se caracteriza por la inclusión de nuevos factores y temas en la plasmación literaria de la realidad. En primer lugar, introduce la tragedia, la adversidad y la injusticia, en el mundo de las tradiciones patriarcales, optimistas e ingenuas, del costumbrismo. En segundo lugar, inserta el factor social y político, desdeñado tradicionalmente por el costumbrismo, como un recurso necesario para explicar ciertas formas de comportamiento y ciertas actitudes de los personajes.

La aparición de estos factores, consideramos nosotros, puede tomarse como un síntoma de las limitaciones del sistema literario costumbrista, incapaz ya de abarcar y relacionar todos los aspec. tos y fenómenos de la vida costarricense de la época. Es síntoma de la necesidad de un nuevo sistema que, al integrar todos estos factores, forje una imagen más completa y más profunda -exhaustiva- del mundo costarricense. Pero, además, la inclusión de estos factores significa, no solamente un cambio en el modo de expresión literaria, sino también un indicio de transformación en la actitud de los autores $-\mathrm{y}$ de los hombres de la época - hacia la realidad circundante y hacia la validez unívoca del mundo y las costumbres patriarcales, que expresaba el costumbrismo.

El costumbrismo es índice de la expansión de la literatura y de la cultura en general, hacia capas más amplias de la población; hecho que responde, presumiblemente, a las reformas político-educativas introducidas en la vida nacional por los liberales de fines del siglo XIX. El carácter popular del costumbrismo es evidente si se comparan la personalidady las obras de Magón y Aquileo, con las de los cronistas históricos Manuel de Jesús Jiménez, Manuel Argüello Mora y Ricardo Fernández Guardia. El hecho es manifiesto, tanto en la procedencia y posición social de los autores, como en la introducción de temas, personajes y un lenguaje, más cercanos a la vida cotidiana y popular.

Sin embargo, su enfoque de la vida popular parte de cierta idealización de las costumbres y tradiciones patriarcales y campesinas, en que la tragedia, los vicios e injusticias sociales y morales, se diluyen, absorbidos por el giro pintoresco o la anécdota divertida. El mundo del costumbrismo anecdótico es un mundo plano, armónico, sin fisuras. La actitud anecdótica implica, en este sentido, una actitud de ingenuo optimismo y de plena confianza -apenas disimulados por una tenue ironía y cierta burla socarrona- en la validez moral, y la necesidad incuestionable de las costumbres, los valores y las relaciones sociales establecidas.

La inclusión, en algunos textos literarios costumbristas, de elementos que conducen a la desgracia o la tragedia; la consideración de factores sociales y políticos, que determinan el destino de los héroes; implican la aparición de una actitud de duda, de cuestionamiento ante la realidad, una ruptura con la fe optimista e ingenua en la bondad y la justicia del mundo de los valores y relaciones patriarcales. Esta actitud de duda y ruptura no se manifiesta, sin embargo, en $\mathrm{Ma}$ gón y Aquileo, en forma explícita. No hay crítica o denuncia explícitas de un sistema social que genera actitudes inmorales e injustas. Este último tipo de crítica, que sí aparece con cierta 
claridad en algunas obras de Fernández Guardia (El estreno, La política), sólo será registrado con plena consciencia en la obra de García Monge. Creemos, sin embargo, que la introducción de los factores trágicos, sociales y políticos, antes mencionados, son un indicio de una actitud crítica -no por implícita menos patente-, y constituyen en cierta medida un rompimiento con el mundo tradicional del costumbrismo. Las páginas siguientes deberán ser consideradas como un aporte provisional, que estudia la aparición de esos elementos en algunas obras de Magón y Aquileo. Ellas formarían parte de un estudio posterior, más completo, que habría de investigar el desarrollo de las diversas manifestaciones -esporádicas y casuales en el costumbrismo- de esa nueva actitu crítica, hasta integrarse coherentemente, en la obra de García Monge, en un nuevo sistema literario, expresión, a su vez, de una nueva visión del mundo, una nueva concepción de la realidad costarricense.

\section{ELEMENTOS CRITICOS EN "LA PROPIA" DE MAGON}

La propia es, en palabras de Abelardo BoniIla, "el único cuento amargo y trágico de Magón" (2). Es el único que muestra una fisura en la superficie siempre alegre y divertida del costumbrismo tradicional. Pero, además, la irrupción de la tragedia en el mundo optimista y plácido del costumbrismo anecdótico, significa, también, el descubrimiento de que, bajo la aparente armonía y solidez de los valores y tradiciones patriarcales, se esconde un mundo de brutalidad, vicio, miseria e ignorancia. Toda la estructura del relato busca hacer patente este descenso del "mundo claro" a un "mundo oscuro". Para lograrlo fue necesario que Magón modificara y enriqueciera su concepción de la realidad y todo el arsenal de sus recursos literarios. La propia es el relato más ambicioso, extenso y mejor estructurado del autor; el "arquetipo antológico" de su obra, en palabras de José M. Arce (3).

Es éste el único cuento de Magón en que el autor se esfuerza por supeditar la descripción de hechos y ambientes -que en el cuadro de costumbres es un fin en sí mismo a la exposición de la suerte o el destino de los personajes. La figura humana, que en el cuadro de costumbres era un accesorio o un objeto más en el conjunto, pasa a ocupar aquí un lugar en el proscenio. La descripción de una anécdota o una escena, es susti- tuida por la relación del destino de Oconitrillo y su familia, que sirve de engarce a la diversidad de escenas y ambientes del relato. Este cambio exige otros: mayor extensión y amplitud en el argumento, la inclusión de áreas más variadas de la realidad, y el empleo de recursos estilísticos y temáticos más complejos.

En sus rasgos esenciales, la primera parte casi no se diferencia del cuadro de costumbres. Hay, eso sí, una posición más impersonal, más objetiva, que la acostumbrada en los otros cuentos de Magón, de parte del narrador. En los demás cuadros de costumbres el lenguaje y el punto de vista del narrador se identificaban con el de un observador personal, casi siempre el propio autor-narrador, que relata lo observado en primera persona; en La propia, el narrador es mucho más impersonal y neutro. Esta nueva modalidad narrativa se adapta mejor, indudablemente, a los propósitos del autor en este relato. Ella permite mayor movilidad y amplitud en las descripciones, la inclusión de más diversos y heterogéneos factores en el retrato y caracterización de los personajes, $y$, sobre todo, la posibilidad de emplear más variados recursos y tonos narrativos, en conformidad con la mayor complejidad argumental y temática.

La primera parte de La propia es una de las más perfectas muestras del arte descriptivo de $\mathrm{Ma}$ gón. El pincel del narrador pasa con extraordinario vigor, movilidad y penetrante observación, de la casa al cafetal, de la familia Oconitrillo a las ingentes $\mathrm{y}$ abigarradas actividades de sus peones.

"... un mocetón robusto, cubierto de sudor y polvo, no da punto de reposo al manubrio del Campeón, que avienta y clasifica el café con sonidos de cascada que fingen los granos al revolverse entre el cilindro espiral de la criba de alambre...

A lo largo de las paredes del corredor están las esco. gedoras apartando con primor los granos negros y quebrados sobre las lisas tablas de las mesas... No paran las manos, ora persiguiendo el negro, ora entresacando el pedazo, apartando los palillos, espulgando los terron. citos y las piedrecillas...

Los mocetones alzan en vilo, con un vigoroso empuje de caderas, los sacos repletos y se los encajan en la mem. bruda espalda... Pela un muchacho con su afilado "Colis" las sabrosas cañas y partiéndolas en cabos, las ataruga en los hocicos de los bueyes...

Como granizada resuena en el patio el café que los peones remueven con palas de madera, unos extendiendo el mojado, otros volteando el que está a medio palo, otros amontonando el seco" (4). 
El cuadro es un derroche de color y movimiento; de esfuerzo y trabajo, alegre, sano y productivo, que se identifica con la fuerza y plenitud de la naturaleza, del "sol de febrero, rojo como cara de borracho, quemante, abrasador, llenando de vida exhuberante la campiña... metiendo sus rayos como hojas de machete nuevo entre las breñas" (5).

El retrato de Ñor Julián Oconitrillo ("gamonal y tagarote de peso en todo el cantón, en donde en lo administrativo es Munícipe del llustre Ayuntamiento, en lo religioso, Vice-presidente de la Junta de Edificación del Nuevo Templo, y en lo político, es nada menosque Presidente Honorario del Gran Partido Progresista...") Ilama la atención por la amplitud y variedad de rasgos (trabajo, dinero, importancia social, política, religiosa) que Magón, en forma desusada para sus cuentos, combina para caracterizar aquí a su personaje.

La hábil utilización de todos estos recursos no hace más que acentuar la impresión de solidez, optimismo, armonía y exhuberancia vital de este "mundo claro" y confiado de tradiciones, costumbres y relaciones patriarcales.

Pero, a partir de la pasión inmoderada que hace surgir María Engracia en el alma de ñor Julián, todo cambia; la armonía y estabilidad del "mundo claro" se desgarran y se desencadena una serie de acontecimientos, inesperados e incontrolables. Magón nos lleva a descubrir, en el ininterrumpido "descenso a los infiernos" de Julián Oconitrillo, el lado oculto que se escondía tras la arcadia patriarcal: un mundo oscuro de bestialidad, vicio y miseria. La tragedia y la destrucción moral y material, terminan por contaminar a toda la familia Oconitrillo.

En la relación de estos hechos, el arte de Magón alcanza el máximo de posibilidades y recursos, haciendo resonar notas inéditas, que nunca -ni antes ni después- habría de emplear de nuevo el autor. Abelardo Bonilla anota cómo en las últimas escenas "los rasgos naturalistas de La propia, excepcionales en el conjunto de la obra, se acercan a lo expresionista" (7). La fuerza humana y exhuberancia vital de las primeras escenas, contrasta con estas últimas, donde la visión de la realidad, amarga y deshumanizada, raya en lo repulsivo y lo grotesco.

"...una tremenda puñalada le dividía la carótida izquierda; brotó la sangre en espumoso chorro y una voz de angustia infinita hendió siniestramente las aires en el silencio de la noche, volviendo el pesado cuerpo a desga- jarse entre la cuja... El asesino seguía apuñaleando a su víctima con saña fiera, lanzando imprecaciones espeluznantes y carcajadas aterradoras...

Ya en las cercanías de la cárcel, dos mujercillas agarradas furiosamente de los moños, se revolcaban en el hediondo caño, cubriéndose de arañazos y denuestos; la "Cinco Pelos", enclenque y desmedrada, llevaba la peor parte..." (8).

La actitud crítica se manifiesta aquí, en el tono amargo y pesimista, que indica la pérdida de fe del autor, en el sentido unívoco y estable del mundo patriarcal. Pero no aparece en forma explícita y consciente. No hay un análisis de las causas del resquebrajamiento de los valores morales, ni una crítica de las costumbres e instituciones políticas y sociales.

Los valores y estructuras morales y sociales que conforman la vida patriarcal, no son determinantes, en la obra, para la caída de Julián en el mundo oscuro al que lo arrastra su destino. Es este "destino" de ñor Julián, el que sirve de unión entre los dos mundos. Pero este destino obedece, en el cuento, a causas fortuitas, a factores individuales y personales; son un defecto en el carácter de Oconitrillo, que se deja arrastrar por la pasión y el instinto, su "antojo" por María Engracia, circunstancias todas externas y ajenas a los valores patriarcales.

La relación entre la armonía patriarcal y la tragedia es, en el relato, puramente casual; no causal. Los valores que rigen la vida en el mundo claro, son independientes y autónomos; no tienen relación causal con los valores y la vida, que rigen en el submundo del vicio, la prostitución, la brutalidad y la miseria. La existencia del "mundo oscuro", por lo tanto, no pone en duda, en la obra, la integridad de los valores morales y sociales del mundo patriarcal.

\section{ELEMENTOS CRITICOS EN LAS "CONCHE. RIAS" DE AQUILEO ECHEVERRIA}

Dos de las "concherías" presentan rasgos que las diferencian de las demás y que significan una innovación, una forma inédita de ver y considerar los hombres y las cosas, en la concepción literaria de Aquileo Echeverría.

Diálogo es la única obra de Aquileo (y del costumbrismo en general) en que aparece un intento de transmitir el significado de los hechos desde el interior, desde la conciencia del personaje. Esta diferencia se hace palpable si comparamos Diálogo con otra "conchería": Visita de pé- 
same. Ambas tratan el mismo tema: la muerte del marido de una de las interlocutoras, pero el punto de vista desde el cual es enfocado y la manera de tratarlo son muy diversas.

En Visita de pésame se enfoca el aspecto anecdótico de la enfermedad y la muerte del marido; las convenciones y ritos sociales populares que este hecho genera. Todo está tratado en un tono impersonal, emocionalmente neutro y puramente informativo. Se utiliza un lenguaje marcadamente pintoresco y folclórico, y se hace énfasis en la repetición de giros, palabras, y situaciones "cliché", que la celebración del acto tradicional del pésame implica.

\footnotetext{
"Al puro "tan" de las doses volvió a manijar la lengua, soltó un quejido muy largo, dijo unas palabras feas, se pegó dos estirones, sacó la panza pa juera, boltió los ojos en blanco, y'hiso como cuatro muecas... ildiay se quedó dijunto!...

- L'espero pa'l novenario... porque va a estar muy alegre. Tata mató una ternera y tres garrafas de guaro y seis frascos de mistela, y además ha contratao cuatro músicos de Heredia; y pa los misterios tiene cuetes de lus y bombetas..."
}

El resultado es el común en el cuadro de costumbres: el hecho trágico deja de serlo. Al suprimir la relación entre los hechos descritos y la conciencia o los sentimientos de los personajes, se convierte en graciosa y divertida narración de una simple anécdota, ingeniosamente salpicada de costumbres y giros populares.

En Diálogo, en cambio, los detalles anecdóticos han sido reducidos en gran medida, y lo que domina es más bien la expresión de los sentimientos, que la muerte del marido producen en la viuda.

\footnotetext{
"Pero, a mi iquién me quita que me haga tanta falta? Tengo como congoja, tengo como unas ganas como de meniame y estar acurrucada, sin que naide me viera, íngrima en este cuarto, íngrima en esta casa,
}

así como los mertos, así como enterrada. ¿Sabés cómo me encuentro?

Como un moto sin mama... (10)

Es un cambio importante en la actitud del narrador hacia sus personajes; y el único intento del autor de las Concherías, por pasar, de la descripción de los detalles externos, a la expresión de la emoción, sucitada por lo externo, en el alma o la conciencia del personaje.

El tono dominante no es, como en Visita de pésame, impersonal y neutro; sino un tono lírico, cargado de emoción y sentimiento. La actitud hacia el personaje no es de burla o sorna; hay más bien compasión y conmiseración, ante el dolor y la soledad de la esposa viuda. El personaje no es, en Diálogo, un objeto más en un cuadro de costumbres; es un ser consciente, capaz de captar y tamizar con sus sentimientos, juicios y emociones, el significado de los hechos, y darles un nuevo sentido. El Aquileo de Diálogo puede considerarse un precursor del realismo sentimental (o "estilización del realismo", como lo Ilama Abelardo Bonilla(11)) de los primeros relatos de Luis Dobles Segreda y Carmen Lyra.

En Diálogo, como en La propia, hay un rompimiento - no por sutil menos importanteen la actitud hacia la realidad, del autor costumbrista. La introducción de la conciencia del personaje lleva a la posibilidad de diversos juicios, o puntos de vista, sobre el valor o el significado de los hechos. Las tradiciones y valores convencionalmente aceptados, y en cuya evocación o recreación se complace el autor costumbrista, son vistos desde un ángulo distinto al del observador externo: el "leva" simpático y "chota", que se divierte contemplando y describiendo lo que racen los "conchos". Ahora vemos el significado que esos mismos hechos adquieren para la vida y la conciencia de los personajes afectados. Surge una actitud de duda hacia la validez, univocidad y estabilidad de la realidad objetiva, y de las convenciones sociales que la rigen. Lleva al descubrimiento de que, bajo los mismos hechos que provocan diversión y burla, se esconde, latente, un mundo de dolor y tragedia; sólo hay que variar nuestro ángulo de observación, nuestra actitud hacia la realidad y los hombres, para hacerlo patente.

En La firmita es más obvia la ampliación y la integración, que hace Aquileo, de nuevos fac- 
tores en el mundo del costumbrismo tradicional. En esta "conchería" la actitud crítica ante el mundo de las convenciones patriarcales, no se limita a develar el lado oscuro y trágico, desde un punto de vista puramente incividual y particular.

La firmita introduce en el mundo de las costumbres patriarcales un nuevo factor: el factor político. Pero es este un factor que produce un cambio cualitativo en la actitud hacia el mundo de la literatura costumbrista, y un cambio radical con respecto a las manifestasiones críticas implícitas en La propia o Diálogo. La actitud de crítica y de duda se limitaba, en dichas obras, a señalar, que, tras el mundo patriarcal, claro y armónico, existe un mundo oscuro, doloroso y trágico. Pero la causa de la desgracia era, en ambos casos, un hecho accidental e individual; no tenía, en estas obras, raíces sociales y no ponía en duda, por io tanto, la validez del sistema político-social que rige la vida patriarcal.

La introducción del factor político conlleva toda una transformación en la actitud del autor hacia la realidad; el eje se traslada del destino individual a las instituciones político-sociales, que son las que determinan la vida, el comportamiento, y las relaciones entre los hombres. Esta "conchería" pone en tela de juicio la validez y la justicia de todo el sistema de vida patriarcal, en su conjunto, al poner al descubierto la falsedad intrínseca de sus estructuras políticoelectorales. Lo que produce la desgracia y la confusión del campesino de La firmita, es su alienación política, su incapacidad para comprender y dominar unas estructuras político electorales que, debiendo servirle a él para la expresión y manifestación de su voluntad, se convierten más bien en un sutil instrumento, extraño a sus intereses y ajeno a su voluntad, por medio del cual se le manipula, se le obliga inconscientemente a servir designios ajenos, para él oscuros e incomprensibles.

La firmita traslada el eje de la contraposición "mundo claro-mundo oscuro", del plano de lo accidental-individual, al plano de las estructuras político-sociales; lo que era oposición entre dos entes independientes, aparece ahora como las dos caras de una misma moneda. Las mismas estructuras político-sociales, que engendran los valores patriarcales, llevan implícito en su seno la capacidad de convertirse también en instrumento de desgracia, opresión e injusticia. El autor lo advierte con sólo ampliar su án- gulo de observación o análisis de la realidad, trasladándolo, de la descripción de hechos e individuos aislados, a las relaciones y estructuras sociales.

Aquileo, sin embargo, no lleva hasta sus últimas conclusiones, las premisas críticas en que descansa $\mathrm{La}$ firmita. No intenta poner de relieve las consecuencias de tipo moral y ético, a que nos llevaría la denuncia de todo un sistema político-social basado en el engaño, en la contradicción entre los principios que aparenta sostener y la realidad que se esconde tras esos principios. Aquileo, más bien, trata de disimular esas consecuencias. Así, la crítica de La firmita, curiosamente, no llega a convertirse en protesta o denuncia explícita. La desoladora experiencia del héroe no lo lleva a rebelarse contra la inmoralidad y la injusticia de un sistema político-social que lo traiciona y lo mutila. Su conclusión es, más bien, que lo sucedido es un castigo merecido, por querer intervenir en lo que le está vedado. Su deducción, expresada en los versos finales, es que son los "levudos" quienes deben gobernar; los "descalzos" limitarse a trabajar y obedecer.

\footnotetext{
"Dejémosle a los que saben... que busquen entr'ellos quien mande, si bien los manda...

$Y$ si los otros queremos de veras a la Patria escribamos con el sacho, discursiemos con la pala, porque el día que los metamos nosotros a legislala

se muere di'hambre la gente: la levuda y la descalsa" (12).
}

El tono y el estilo de la obra corresponden también a esta peculiar posición del autor-narrador ante lo relatado. La inclusión de nuevos factores en el contenido de la conchería, parecía implicar una actitud distinta del autor hacia la realidad plasmada; pero en lo formal, La firmita no deja de ser otro cuadro idealizado de costumbres, semejante a las otras concherías. El desengaño y la frustración, que producen en el campesino los acontecimientos políticos, están relatados en el mismo tono festivo y socarrón, y la impresión que deja en el lector no es de indignación o molestia ante la farsa y la manipulación político-electoral, sino la sensación, entre burlona $y$ divertida, de haber asistido a otro cuadro de costumbres más. Al utilizar la misma manera y los mismos recursos de plasmación literaria, que 
emplea en las demás concherías, Aquileo logra neutralizar y diluir la fuerza de las implicaciones morales y sociales, que parecían desprenderse de los nuevos contenidos políticos insertados en el cuadro costumbrista.

De esta manera, la actitud crítica del autor de La firmita permanece implícita, en el reconocimiento de la importancia y la necesidad del factor político para la plasmación literaria de la vida y la realidad costarricenses; pero no se convierte en denuncia explícita, o protesta, contra las deformaciones morales y humanas, que la injusticia y la opresión político-sociales traen consigo.

En conclusión, podemos afirmar que los elementos críticos en Magón y Aquileo, no pasan de tener una aparición esporádica en el conjunto de su obra; y una manifestación no del todo definitiva y consecuente en las obras donde aparecen. Son siempre elementos aislados, que ponen en duda, pero no llegan a transformar la concepción costumbrista patriarcal de la realidad.

Corresponderá a Joaquín García Monge cor.vertirse - con El Moto e Hijas del campo- en el portavoz de una nueva generación literaria. El logrará reunir y dar coherencia a los elementos críticos, desperdigados en la obra de los autores costumbristas, amalgamarlos en una nueva unidad y un nuevo sistema literario, para expresar una concepción inédita del mundo y la realidad costarricenses. Su estudio y descripción serían tema para otro artículo.

\section{NOTAS}

(1) Bonilla, Abelardo, Historia de la literatura costarricense, Ed. Costa Rica. San José, 1967, p. 109.

(2) Ibid., p. 132.

(3) Arce, José M., "Estudio preliminar", en: Cuentos de Magón, Colección Selectio, San José, 1968, p. $\times X X I I I$.

(4) González Zeledón, Manuel (Magón), op. cit., p. $115-117$.

(5) Ibid., p. 117.

(6) Ibid. p. 116.
(7) Bonilla, A., op. cit., p. 132.

(8) González Zeledón M., op. cit., p. 124.

(9) Echeverría, Aquileo J., Concherias, romances, epigramas y otros poemas, Colección Selectio, San José, s.f.e., p. 166-167.

(10) Ibid., p. 116-117.

(11) Ver: Bonilla A., op. cit., cap. XVI.

(12) Echeverría A., op. cit., p. 190-191.

\section{BIBLIOGRAFIA}

Barahona Jiménez, Luis. Apuntes para una historia de las ideas estéticas en Costa Rica, Ministerio de Cultura, San José, 1982.

Bonilla, Abelardo. Historia de la literatura costarricense, Ed. Costa Rica, San José, 1967.

Castro Rawson, Margarita, El costumbrismo en Costa Rica, Imp. Lehmann, (2 ed.) San José, 1971.

Chase, Alfonso, "Notas para una historia de la narrativa costarricense", en: Narrativa contemporánea de Costa Rica, t.I. Ministerio de Cultura, 1975.
Echeverría, Aquileo J. Concherias, epigramas, romances $y$ otros poemas, Prólogo de Arturo Agüero Ch., Colección Selectio, San José, s.f.e.

Facio, Rodrigo, Estudio sobre economía costarricense, Ed. Costa Rica, San José, 1975.

González Zeledón, Manuel, Cuentos de Magón, Estudio introductorio de José M. Arce, Colección Selectio, San José, 1968.

Luckács, Georg. Problemas del realismo, Fondo de Cultura Económica, México, 1966. 
Sandoval de Fonseca, Virginia, Resumen de literatura costarricense, $\mathrm{Ed}$. Costa $\mathrm{Ri}$ ca, San José, 1978.

Stone, Samuel, La dinastía de los conquista- dores, EDUCA, San José, 1975.

Valdeperas, Jorge. Para una nueva interpretación de la literatura costarricense, Ed. Costa Rica, San José, 1979. 
